\title{
Abscisic Acid in Salt Stress Predisposition to Phytophthora Root and Crown Rot in Tomato and Chrysanthemum
}

\author{
Matthew V. DiLeo, Matthew F. Pye, Tatiana V. Roubtsova, John M. Duniway, \\ James D. MacDonald, David M. Rizzo, and Richard M. Bostock
}

Department of Plant Pathology, University of California, One Shields Ave., Davis 95616.

Current address of M. V. DiLeo: Boyce Thompson Institute for Plant Research, Tower Road, Ithaca, NY 14853-1801.

Accepted for publication 4 May 2010.

\section{ABSTRACT}

DiLeo, M. V., Pye, M. F., Roubtsova, T. V., Duniway, J. M., MacDonald, J. D., Rizzo, D. M., and Bostock, R. M. 2010. Abscisic acid in salt stress predisposition to Phytophthora root and crown rot in tomato and chrysanthemum. Phytopathology 100:871-879.

Plants respond to changes in the environment with complex signaling networks, often under control of phytohormones that generate positive and negative crosstalk among downstream effectors of the response. Accordingly, brief dehydration stresses such as salinity and water deficit, which induce a rapid and transient systemic increase in levels of abscisic acid (ABA), can influence disease response pathways. ABA has been associated with susceptibility of plants to bacteria, fungi, and oomycetes but relatively little attention has been directed at its role in abiotic stress predisposition to root pathogens. This study examines the impact of brief salinity stress on infection of tomato and chrysanthemum roots by Phytophthora spp. Roots of plants in hydroponic culture exposed to a brief episode of salt (sodium chloride) stress prior to or after inoculation were severely diseased relative to nonstressed plants. Tomato roots remained in a predisposed state up to $24 \mathrm{~h}$ following removal from the stress. An increase in root ABA levels in tomato preceded or temporally paralleled the onset of stress-induced susceptibility, with levels declining in roots prior to recovery from the predisposed state. Exogenous ABA could substitute for salt stress and significantly enhanced pathogen colonization and disease development. ABA-deficient tomato mutants lacked the predisposition response, which could be restored by complementation of the mutant with exogenous ABA. In contrast, ethylene, which exacerbates disease symptoms in some host-parasite interactions, did not appear to contribute to the predisposition response. Thus, several lines of evidence support ABA as a critical and dominant factor in the salinity-induced predisposition to Phytophthora spp. infection.

Additional keywords: osmotic stress, Phytophthora capsici, P. cryptogea, P. parasitica.
Plants perceive and respond to dehydration stresses through a complex and dynamic signaling network that permits both immediate survival and long-term stress tolerance (55). Although this network is impacted by the type, frequency, intensity, and duration of the dehydration stress, molecular messengers such as the phytohormone abscisic acid (ABA) play central roles in stress adaptation $(8,28)$. Because plants employ a relatively limited array of phytohormones to coordinate various abiotic and biotic stress responses, crosstalk may occur between what appear to be functionally separate pathways (8).

ABA may represent a node of convergence in crosstalk in dehydration stress and alterations to disease susceptibility. Drought, salinity, and anoxic stresses have all been shown to impact plant responses to pathogen infection $(18,29,32,33,43)$. ABA, the primary dehydration-responsive messenger, has been demonstrated to increase susceptibility or resistance to different pathogens, perhaps reflecting the diversity of pathogenesis mechanisms operative in plant-microbe interactions $(2,5,6,13,19,21,24,34$ $38,52,53)$. In the case of Phytophthora spp. infection, increased levels of ABA likely contribute to the increased susceptibility following transient episodes of dehydration stress $(10,18,29,32$, $33,36)$. This stress-induced susceptibility, or predisposition (11), may operate through an antagonistic relationship with important

Corresponding author: R. M. Bostock; E-mail address: rmbostock@ucdavis.edu

* The $e$-Xtra logo stands for "electronic extra" and indicates that the online version contains five supplemental figures and that Figure 1 appears in color online.

doi:10.1094/PHYTO-100-9-0871

(C) 2010 The American Phytopathological Society disease resistance signals such as salicylic acid, jasmonic acid, and ethylene by altering programmed cell death (PCD) responses or by interfering with resistance-gene-mediated or innate resistance mechanisms $(9,57)$. Although studies have found associations among dehydration stress, ABA, and modifications in plantmicrobe interactions, the underlying molecular mechanisms for predisposition remain unresolved. Furthermore, our emerging understanding of the contribution of ABA to resistance and susceptibility in plant-microbe interactions has been based on studies of foliar pathogens (53). Relatively little information exists concerning mechanisms of predisposition in roots and the associated regulatory signals.

In this study, we initially examined the role of ABA in salinityinduced susceptibility in two Phytophthora spp.-plant interactions using hydroponically grown chrysanthemum (Chrysanthemum morifolium cv. Paragon) and tomato (Solanum lycopersicum) plants. The influence of episodes of salinity stress on the infection of chrysanthemum by $P$. cryptogea has been well characterized $(32,33,49)$. Salinity stress predisposition also has been documented in tomato plants, which are attacked in the field by a number of root- and crown-infecting Phytophthora spp., including $P$. capsici and $P$. parasitica (50). Here, severe but agriculturally relevant levels of salt stress were applied to chrysanthemum and tomato plants in hydroponic systems prior to or after inoculation. Salinity stress imposed under hydroponic growth conditions was chosen as the stress regime for these studies because of the ease of imposing and removing the stress in a uniform and synchronous manner. This study addresses the temporal limits of salinity-induced predisposition in addition to the impact of ABA deficiency. We also evaluated the potential 
contribution of ethylene in the predisposition response of tomato to Phytophthora root and crown rot. Our results provide evidence that ABA is a critical and dominant factor in the salinity-induced enhancement of root susceptibility to Phytophthora spp. infection.

\section{MATERIALS AND METHODS}

Plant material and hydroponic cultivation. Chrysanthemum. Terminal cuttings of $C$. morifolium cv. Paragon were used and propagated as follows. Cuttings were rooted by transfer to a perlite/vermiculite mixture $(1: 1, \mathrm{vol} / \mathrm{vol})$ in a mist chamber for $\approx 10$ to 15 days prior to their transfer to 1.8 -liter ceramic crocks of aerated 0.5× Hoagland's solution (27). The crocks were fitted with opaque plastic lids with holes for the plants, which were secured with sponge rubber strips to suspend their roots in the solution. Once moved to a hydroponic system, plants were permanently covered with clear polyethylene bags to prevent transpirational shock and resulting leaf burn. These cuttings were given a 3-day recovery period in nutrient solution before inoculation or stress treatments. All mother block plants and cuttings were maintained at 20 to $25^{\circ} \mathrm{C}$ in a greenhouse supplemented by $16 \mathrm{~h}$ of incandescent light daily to prevent flowering.

Tomato. Tomato plants (S. lycopersicum cv. New Yorker) were used for most experiments. The homozygous ABA-deficient mutants sitiens, flacca, and notabilis were compared with their isogenic, wild-type (WT) background, 'Rheinlands Ruhm' (51). The homozygous ethylene perception mutant Never ripe $(\mathrm{Nr})$ was compared with its near isogenic, WT background, 'Rutgers'. 'New Yorker' seed were obtained from a commercial source (Totally Tomatoes, Randolph, WI). Seed of the other genotypes used in this study were obtained from the C. M. Rick Tomato Genetics Resource Center at the University of California, Davis, and propagated for seed production in the greenhouse.

Tomato plants were grown in three hydroponic formats: large (6-week-old plants with four to six true leaves), medium (4-weekold plants with two to three true leaves), and small (2-week-old plants with two expanded cotyledons and zero leaves). For the large-format experiments (four- to six-true-leaf stage), tomato seed were first surfaced sterilized with the following treatment sequence: $50 \% \mathrm{HCl}(10 \mathrm{~min})$ and rinsed with sterile deionized $\mathrm{H}_{2} \mathrm{O}, 10 \%$ trisodium phosphate (TSP) (15 min) and rinsed $3 \times$ in sterile deionized $\mathrm{H}_{2} \mathrm{O}, 70 \%$ ethanol $(10 \mathrm{~min}$ ) bleach for $30 \mathrm{~min}$ and rinsed with sterile deionized $\mathrm{H}_{2} \mathrm{O}$, and $50 \%$ commercial bleach (3\% sodium hypochlorite; $20 \mathrm{~min}$ ) followed by sterile deionized $\mathrm{H}_{2} \mathrm{O}$ rinse $(3 \times)$. In the initial experiments, seed were germinated in a perlite/vermiculite mixture and then the seedlings were transplanted to ceramic crocks similar to those used for the chrysanthemum cuttings, with their roots suspended in aerated $0.5 \times$ Hoagland's solution. Seedlings were grown for an additional 4 weeks in a greenhouse until at least four true leaves had developed on each plant. Immediately prior to treatment, plants were moved to a growth chamber $\left(12\right.$-h photoperiod, $22^{\circ} \mathrm{C}, 70 \%$ relative humidity $[\mathrm{RH}]$ ) in ceramic crocks with $0.5 \times$ Hoagland's solution under continuous aeration.

For the medium-format experiments (two-true-leaf stage), surface-sterilized seed were started in germination paper in beakers containing sterile deionized $\mathrm{H}_{2} \mathrm{O}$, transferred to trimmed 5-ml polypropylene pipette tips, secured with foam test tube plugs, and placed into aerated hydroponic containers filled with 4 liters of aerated, $0.5 \times$ Hoagland's solution. Seedlings were grown for an additional 2 weeks in a climate-controlled greenhouse with supplemental lighting until at least two true leaves had developed on each plant. Immediately prior to treatment, plants were moved to a growth chamber $\left(12\right.$-h photoperiod, $22^{\circ} \mathrm{C}, 70 \%$ $\mathrm{RH})$ and placed in individual 50-ml polypropylene tubes filled with $0.5 \times$ Hoagland's solution under continuous aeration.

For the small-format hydroponic experiments (two-cotyledon stage), seedlings were produced as for the two-leaf format but were used immediately within a petri dish format (Supplemental Figure S1B). Prior to treatment, 5 to 10 seedlings were moved to each 15-by-150-mm petri dish, with their radicles placed between two layers of filter paper that were saturated with deionized water (for extracted phenolics experiments) or $0.5 \times$ Hoagland's solution (for quantitative polymerase chain reaction [qPCR] experiments). Plants were kept under fluorescent light (12-h photoperiod) at ambient temperature $\left(23\right.$ to $\left.27^{\circ} \mathrm{C}\right)$.

Pathogen isolates and culture. $P$. parasitica and $P$. cryptogea were obtained from our own collection and are strains used in previous studies $(33,50)$. $P$. parasitica and $P$. cryptogea were originally isolated from diseased tomato and chrysanthemum plants, respectively. A pepper isolate of $P$. capsici (from Yolo County, CA; also from our collection and pathogenic on tomato) was used for most tomato experiments. P. capsici isolate 1509, from the collection of M. Coffey, University of California-Riverside, was part of an earlier project conducted in 1989 to 1992.

Zoospore suspensions were produced with standard techniques (17). P. cryptogea was maintained on pea-dextrose agar at 22 to $24^{\circ} \mathrm{C}$ and zoospore inoculum was prepared as described previously using a filter-sterilized soil extract solution (32). P. parasitica was maintained on V8 juice agar plates at room temperature under fluorescent lights, and zoospore inoculum was prepared in a manner similar to $P$. cryptogea with a filter-sterilized soil extract solution. Soil extract solution was prepared by suspending $100 \mathrm{~g}$ of a steamed "UC Mix"-type potting soil, consisting of equal parts of composted redwood, no. 2 washed sand, peat moss, and white pumice, and $\approx 1 \mathrm{~kg}$ each of oyster shell calcium and dolomite lime per cubic meter, in 1 liter of distilled $\mathrm{H}_{2} \mathrm{O}$ for 3 days. The liquid was filtered through four layers of cheesecloth and then through a series of filters of progressively smaller pore sizes, with final passage through a $0.22-\mu \mathrm{m}$ GS filter (Millipore Corp., Billerica, MA). P. capsici was maintained on V8 agar plates for $48 \mathrm{~h}$, fresh agar was removed from the margin of the growing colonies, and plates were flooded with sterile deionized water and incubated at room temperature under fluorescent lights (16-h photoperiod) for another $48 \mathrm{~h}$. The cultures were chilled to $4{ }^{\circ} \mathrm{C}$ for $30 \mathrm{~min}$ and then allowed to warm to room temperature to trigger zoospore release. Zoospores were counted using a hemacytometer and diluted to achieve a final concentration for root exposure of either $10^{4}$ or $10^{5}$ zoospores $\mathrm{ml}^{-1}$ in $0.5 \times$ Hoagland's solution or deionized $\mathrm{H}_{2} \mathrm{O}$, as indicated.

Salinity stress treatment and inoculation. The salt stress regime selected for these experiments was based on prior studies of root stress predisposition $(10,32)$. The impact of salinity stress differs from other osmotic dehydration stresses primarily in that salt-stressed plants are additionally exposed to abnormally high extracellular concentration of ions such as sodium and chloride (8). The inclusion of calcium helps mitigate the confounding toxicity caused by sodium and emphasizes the osmotic facet of salinity stress, which is likely applicable to other dehydration stresses. Initial experiments were conducted with chrysanthemum plants inoculated with $P$. cryptogea and large-format (four- to sixtrue-leaf stage) tomato plants inoculated with $P$. parasitica. Subsequently, a more detailed study was completed with mediumand small-format tomato plants inoculated with P. capsici.

Chrysanthemum plants were inoculated prior to the imposition of salt stress. Each plant was inoculated by placing the roots directly into $100 \mathrm{ml}$ of aerated soil extract containing P. cryptogea at $10^{4}$ zoospores $\mathrm{ml}^{-1}$ for $4 \mathrm{~h}$. Mock-inoculated control plants were exposed to soil extract without zoospores. After inoculation, plants were subjected to a 24-h salt stress treatment by placing their roots in $10 \mathrm{ml}$ of an aerated $0.5 \times$ Hoagland's solution containing $0.2 \mathrm{M} \mathrm{NaCl}$ and $0.02 \mathrm{M} \mathrm{CaCl}_{2}$ (salt-treated). The plants were then returned to the ceramic crocks until evaluation. Roots of nonstressed control plants were treated in the same manner except exposed to $0.5 \times$ Hoagland's solution throughout. All experiments with chrysanthemum were conducted in the greenhouse. 
The large-format (four- to six-true-leaf stage) tomato plants were exposed to a preinoculation salt stress in order to better assess the time course of predisposition onset and recovery during exposure and following removal from the stress, as well as to assess the impact of other treatments without directly exposing the inoculum to those treatments. For the large-format experiments, roots of tomato plants in ceramic crocks were subjected to a 24-h salt stress treatment as above, and then inoculated by transfer to aerated soil extract containing $P$. parasitica at $10^{4}$ zoospores $\mathrm{ml}^{-1}$. After a 4-h inoculation period, the plants were returned to the ceramic crocks containing aerated $0.5 \times$ Hoagland's solution.

Following these preliminary large-format experiments, tomato plants were inoculated with $P$. capsici within the medium- and small-format assays. For the medium-format experiments (twotrue-leaf stage), plants were subjected to salt stress by replacing the $0.5 \times$ Hoagland's solution with $0.5 \times$ Hoagland's solution amended with $0.2 \mathrm{M} \mathrm{NaCl}$ and $0.02 \mathrm{M} \mathrm{CaCl}_{2}$ within each individual 50-ml polypropylene tube, under continuous aeration for the prescribed number of hours $(1,6$, or $24 \mathrm{~h})$. Plants were returned to $0.5 \times$ Hoagland's solution, allowed to regain turgor and recover for the prescribed number of hours $(2,4$, or $24 \mathrm{~h})$, and then inoculated with zoospores of P. capsici $\left(10^{4}\right.$ or $10^{5} \mathrm{ml}^{-1}$, as indicated). For the small-format experiments (two-cotyledon stage), tomato plants were subjected to salt stress (6 or $16 \mathrm{~h}$ ) by transferring them to filter papers that were saturated with Hoagland's solution amended with $0.2 \mathrm{M} \mathrm{NaCl}$ and $0.02 \mathrm{M} \mathrm{CaCl}_{2}$, then removed to Hoagland's solution-saturated filter papers for $2 \mathrm{~h}$ to recover. Prior to inoculation, hypocotyls were elevated slightly with either a microscope slide covered with Parafilm (extracted phenolics experiments) or a small cradle of quarter-inch-diameter plastic tubing (qPCR experiments). Each hypocotyl was inoculated at its midpoint with a $10-\mu \mathrm{l}$ drop containing $P$. capsici at $10^{4}$ zoospores $\mathrm{ml}^{-1}$ or a water control.

Disease evaluation and statistical analysis. Disease was evaluated by several methods, depending on the host species and experimental format. For chrysanthemum, entire root systems were excised 6 days after inoculation and placed in a petri dish with water. Main roots (i.e., the three to four largest roots from each plant) were assessed with the aid of a microscope for disease lesions, and were placed in one of three categories: (i) healthy, (ii) $<50 \%$ of root lesioned, or (iii) $>50 \%$ of root lesioned. The experiment was performed three times, with three to six plants per treatment within each experiment, and the data were analyzed using $\chi^{2}$ analysis as performed in JMP software (version 8.0; SAS Inc., Cary, NC). For the medium-format tomato experiments (two-true-leaf stage), P. capsici-inoculated seedlings developed root necrosis that progressed upward into the hypocotyl, leading to stem failure and seedling collapse (Supplemental Figure S1A). Measuring the time until seedling collapse proved to be a reproducible and quantifiable method of measuring susceptibility. Seedling status was checked twice daily and evaluated with survival analysis using the LIFETEST procedure of SAS 9.1 (SAS Inc.). Each independent experiment consisted of four treatments within a completely randomized design. Four independent experiments were combined for analysis of salinity and recovery duration while two independent experiments were combined for analysis of ABA-deficient mutants. Treatments were compared using Bonferroni adjustments of the log-rank test. Disease development of tomato seedlings in the small-format experiments (two-cotyledon stage) was evaluated 48 to $72 \mathrm{~h}$ postinoculation (hpi) by extraction of oxidized phenolics associated with lesions or by qPCR (described below).

Tissue-browning and necrosis assay. Lesion severity was measured (two-cotyledon stage), in part, by the base-extractable, phenolic oxidation products associated with the brown, discolored tissue of infected hypocotyls (25). The assay is sensitive and rapid, can be performed with a single hypocotyl section, and corresponds well to the visual severity of disease with increasing inoculum density (Supplemental Figure S2). Individual hypocotyl sections were placed in methanol overnight to remove free phenols and pigments, and the methanol was decanted and then the hypocotyl sections placed in hot $\left(90\right.$ to $\left.95^{\circ} \mathrm{C}\right) 0.5 \mathrm{~N} \mathrm{NaOH}$ to remove esterified, oxidized phenols. The absorbance of the resulting solution was measured at $405 \mathrm{~nm}$ on a Molecular Devices Vmax microtiter plate reader with Softmax data analysis software (Molecular Devices Corp., Sunnyvale, CA).

Pathogen DNA quantitation in infected host tissue and statistical analysis. Tomato seedlings were frozen in liquid $\mathrm{N}_{2}$, macerated with a FastPrep tissue homogenizer (MP Biomedicals, Solon, $\mathrm{OH}$ ), and extracted with DNeasy Plant Mini kits (Qiagen, Valencia, CA). Pathogen DNA was quantified with a 7500 realtime PCR thermocycler (Applied Biosystems, Foster City, CA) with established primers for $P$. capsici (Cap-FW 5'-TTTAG TTGGGGGTCTTGTACC-3' and Cap-RV1 5'-CCTCCACAA CCAGCAACA-3') (48). Standard curves were verified for this system with pure $P$. capsici DNA $\left(R^{2}=0.99\right)$ and $P$. capsici DNA amended with $100 \mathrm{ng}$ of tomato DNA $\left(R^{2}=0.99\right)$. The relationship of disease and pathogen DNA content determined by qPCR of infected tomato tissue corresponded well at 48 and $72 \mathrm{hpi}$. In addition, we evaluated tomato actin content of healthy and infected seedlings by qPCR using plant actin primers. Our intent was to use actin as an internal standard to provide a basis for normalizing across samples. However, we found that, with greater disease severity, the recovery of actin declined, indicating degradation of host DNA. Thus, to correct for variability across samples, a similar amount of hypocotyl and root tissue was extracted for each sample and the qPCR analyses were performed on DNA extracts adjusted for total DNA content as measured with a Nanodrop Spectrophotometer model ND-1000 (Thermo Fisher Scientific Inc., Wilmington, DE).

To estimate the progression of $P$. capsici colonization in tomato seedlings by qPCR, WT plants (cv. New Yorker) were frozen in liquid $\mathrm{N}_{2}$ at $6,24,48$, and $72 \mathrm{hpi}$, and stored at $-80^{\circ} \mathrm{C}$ until extraction and analysis. Sitiens seedlings used in ABA complementation experiments were exposed to saturated filter paper amended with 38 or $380 \mu \mathrm{M}$ ABA for $24 \mathrm{~h}$ prior to $2 \mathrm{~h}$ of recovery without exogenous $\mathrm{ABA}$, then inoculated. ABA-amended filter paper was covered by aluminum foil to avoid light-mediated degradation of ABA. Because the qPCR data did not satisfy the analysis of variance (ANOVA) criterion for normality, the Wilcoxon rank sums tests were used for means comparisons. Statistical analyses were performed using JMP software (version 8.0; SAS Inc.).

ABA and fluridone treatments. A stock solution of ( \pm )cis,trans-ABA (Sigma-Aldrich, St. Louis) was prepared by dissolving ABA in a small volume of ethanol and then diluting this with water (final ethanol concentration $<0.1 \%$ ). Treatment concentrations of $\mathrm{ABA}$ are reported as the racemic $( \pm)$ mixture, although what is generally considered the biologically active (+)ABA form represents approximately half of the mixture. Roots of hydroponically grown chrysanthemum plants that had been inoculated were transferred to vials containing $10 \mathrm{ml}$ of various concentrations of ABA in aerated $0.5 \times$ Hoagland's solution for $24 \mathrm{~h}$, and then returned to the ceramic crocks as described above. For the tomato seedling assays, seedlings were placed with their roots in small vials containing ABA for $24 \mathrm{~h}$. Seedlings were treated with fluridone (1-methyl-3-phenyl-5-[3-(trifluoromethyl)phenyl]$4(1 H)$-pyridinone; Sigma-Aldrich), an inhibitor of ABA biosynthesis (14), by placing their roots in small vials containing 10, 50, or $100 \mu \mathrm{M}$ fluridone in water for $\approx 8 \mathrm{~h}$. A 1-liter stock solution of $100 \mu \mathrm{M}$ fluridone was prepared by dissolving $32.9 \mathrm{mg}$ of fluridone in $10 \mathrm{ml}$ of acetone, and diluting this solution to $1 \%$ acetone with deionized water containing $0.01 \%$ Tween-20. Fluridone solutions $(10$ and $50 \mu \mathrm{M})$ were prepared from this stock solution in $1 \%$ acetone containing $0.01 \%$ Tween-20. Roots were immersed 
for $8 \mathrm{~h}$ in the fluridone treatment solutions and then transferred for $16 \mathrm{~h}$ to fresh solutions of 10,50 , or $100 \mu \mathrm{M}$ fluridone or to fluridone solutions containing $0.2 \mathrm{M} \mathrm{NaCl}$ and $0.02 \mathrm{M} \mathrm{CaCl}_{2}$. The control treatment was $1 \%$ acetone containing $0.01 \%$ Tween-20
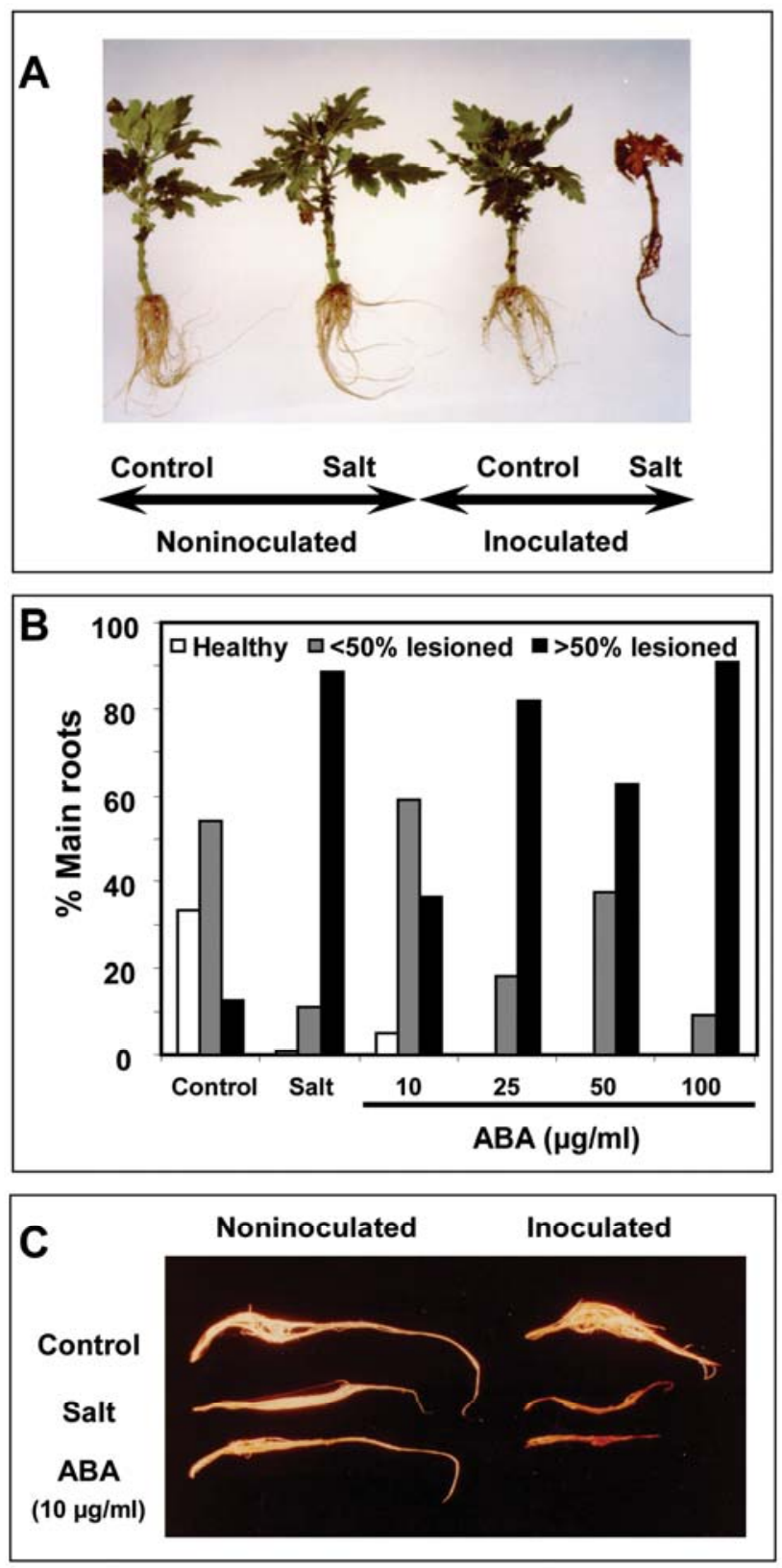

Fig. 1. Effect of salt stress and abscisic acid (ABA) on the development of Phytophthora root rot. A, Impact of salt stress on root rot of chrysanthemum plants caused by Phytophthora cryptogea. Roots were exposed to a zoospore suspension $\left(10^{4} \mathrm{ml}^{-1}\right)$ for $4 \mathrm{~h}$ in $0.5 \times$ Hoagland's solution, and then transferred to $0.5 \times$ Hoagland's solution containing $0.2 \mathrm{M} \mathrm{NaCl}$ and $0.02 \mathrm{M} \mathrm{CaCl}_{2}$ for $24 \mathrm{~h}$. Plants were returned to $0.5 \times$ Hoagland's solution until evaluation 7 days later. B, Effect of exogenous ABA substituted for salt treatment on disease severity as estimated visually by root lesion area in chrysanthemum. Treatment of inoculated roots with ( \pm )-ABA at 10 and $25 \mu \mathrm{g} \mathrm{ml}{ }^{-1}$ (38 and $95 \mu \mathrm{M})$ resulted in disease symptom expression similar to that pictured for the salt stressed and inoculated treatment in A. Data are the average of three independent experiments, with three to six plants per treatment in each experiment. Proportion of roots in the $>50 \%$ lesioned category is significantly greater in plants treated with salt or $\mathrm{ABA}$ at all concentrations tested relative to the control by $\chi^{2}$ analysis $(P \leq 0.05)$. C, Effect of inoculation with P. parasitica $\left(10^{4}\right.$ zoospores $\left.\mathrm{ml}^{-1}\right)$ and salt stress or $( \pm)$-ABA $\left(10 \mu \mathrm{g} \mathrm{ml}^{-1}\right.$; $38 \mu \mathrm{M}$ ) on root rot in tomato. Imposition of treatments was as in A, except plants were inoculated after salt treatment. Roots were excised from the plants 7 days after inoculation for the photograph. without fluridone. After $16 \mathrm{~h}$, all plants were removed from their treatment solutions and allowed to recover ( 1 to $2 \mathrm{~h}$ ) prior to inoculation with $P$. capsici $\left(10^{4}\right.$ zoospores $\left.\mathrm{ml}^{-1}\right)$ in $\mathrm{dH}_{2} \mathrm{O}$. Following inoculation, the seedlings were incubated for $48 \mathrm{~h}$ and evaluated. To determine whether there was an effect on zoospore motility and chemotaxis, a microcapillary swim-in assay similar to that described by Morris and Ward (42) was used with exudates collected from tomato roots that had been treated with solutions with or without $100 \mu \mathrm{M}$ fluridone.

ABA analyses. Root or hypocotyl tissues were collected and immediately frozen in liquid $\mathrm{N}_{2}$. The tissues were lypophilized and placed at $-20^{\circ} \mathrm{C}$ until extraction. The lypophilized tissue was ground in liquid $\mathrm{N}_{2}$ to a fine powder with a mortar and pestle, and three 50- to 100-mg samples were collected and placed in a microfuge tube. Cold $80 \%$ methanol $(1.2 \mathrm{ml})$ containing butylated hydroxytoluene at $10 \mu \mathrm{g} \mathrm{ml}^{-1}$ was added to each tube, which was then vortexed. The extracts were placed in a refrigerator and agitated occasionally for $30 \mathrm{~min}$. The tubes were centrifuged for $5 \mathrm{~min}$ at $10,000 \times \mathrm{g}$, and the supernatants collected. The pellet was extracted with $0.5 \mathrm{ml}$ of $80 \%$ methanol and centrifuged to collect the supernatant. This step was repeated, all three supernatants combined, and the methanol concentration of the extract adjusted to $70 \%$. The extracts were applied to prewet Sep-pak C18 columns (Waters, Inc., Milford, MA) and eluted with $5 \mathrm{ml}$ of $70 \%$ methanol. The eluate $(\approx 7.5 \mathrm{ml})$ containing ABA was concentrated to near dryness at $37^{\circ} \mathrm{C}$ under vacuum and the volume adjusted to $300 \mu \mathrm{l}$ with deionized water. The samples were analyzed by competitive immunoassay (12) with a monoclonal antibody specific for the biologically active (+)-ABA isomer, or with the ABA immunoassay kit according to the manufacturer's directions (Agdia/Phytodetek, Elkhart, IN). Results are expressed as nmoles of (+)-ABA per gram dry weight of tissue.

Ethylene analyses. Ethylene production in hydroponic tomato seedlings was determined in the following manner. Ten seedlings, each with three true leaves, were transferred to a plastic container with their roots submerged in $0.5 \times$ Hoagland's solution or the salt treatment solution. The plants and containers were immediately placed inside a 3.8-liter glass jar, which was then capped with a large cork fitted with a gas sampling tube. The plants remained in the glass chamber at $23 \pm 2{ }^{\circ} \mathrm{C}$ under fluorescent room lighting, and a $10-\mathrm{cm}^{3}$ gas sample was taken for analysis after $16 \mathrm{~h}$. Ethylene determinations were made with a Carle Analytical Gas Chromatograph (model 211; Chandler Engineering, Tulsa, OK) equipped with a flame ionization detector using $\mathrm{N}_{2}$ carrier gas at $80^{\circ} \mathrm{C}$ and a custom-packed, 4-ft. by 1/8-in. stainless steel column containing $8 \% \mathrm{NaCl}$ on alumina $\mathrm{F} 1,80 / 100$ mesh (Supelco; Sigma-Aldrich). Fresh weight of the plants was recorded after blotting the roots to remove excess moisture. The results are expressed as the rate of ethylene evolution in microliters per kilogram per hour. Rheinlands Ruhm, sitiens, Rutgers, and $\mathrm{Nr}$ plants were evaluated, with the mutant genotype compared with its corresponding WT control for each treatment. The experiment was performed three times, and the data were analyzed using ANOVA and Tukey's highly significant difference test as performed in JMP software (version 8.0; SAS Inc.).

\section{RESULTS}

Observations on predisposition with hydroponically grown plants. Hydroponically grown chrysanthemum plants inoculated with $P$. cryptogea and then exposed to a 24-h episode of salt $(\mathrm{NaCl})$ stress were severely affected by Phytophthora root rot, consistent with previous studies with potted plants in a soil mixture (32,33). Within 6 days after inoculation, salt-stressed plants displayed extensive root and stem necrosis, whereas the nonstressed but inoculated plants showed relatively mild symptoms (Fig. 1A). When inoculated roots were treated with ( \pm )-ABA (10 or $25 \mu \mathrm{g} \mathrm{ml} l^{-1} ; 38$ or $95 \mu \mathrm{M}$ ) or salt, the percentage of main 
roots with $>50 \%$ of their length with Phytophthora lesions was significantly greater than in the inoculated, nonstressed controls (Fig. 1B; by $\chi^{2}$ analysis, $P \leq 0.05$ ). Inoculated roots exposed to ABA were similar in symptom appearance to the inoculated salttreated roots.

A similar effect of salt and ABA was observed with the largeformat tomato experiments (four- to six-true-leaf stage). Tomato roots inoculated with zoospores of $P$. parasitica and treated with salt or ABA had extensive root necrosis developing within 1 week after inoculation relative to the nonstressed, inoculated controls, which had only mild symptoms (Fig. 1C).

Time course for predisposition onset and recovery in medium- and small-format tomato seedling assays. The results from the large-format chrysanthemum and tomato experiments provided compelling reason to explore the interaction of abiotic root stress and Phytophthora root and crown rot with greater precision. The interaction between tomato and $P$. capsici was selected for further study because the host has a number of ABAdeficient ("wilty") and other mutants relevant to the central questions of this study, and $P$. capsici is an important pathogen of Solanaceous hosts and has become one of the model Phytophthora spp. with genome sequence information (22).

To determine the time required for predisposition onset and recovery under the hydroponic regime used in our experiments, tomato seedlings at the two-true-leaf stage were exposed to salt for various periods, provided a recovery period of varying duration, and then inoculated with zoospores of $P$. capsici and evaluated (Supplemental Figure S1). Exposure to either 6 or $24 \mathrm{~h}$ but not $1 \mathrm{~h}$ of salinity stress significantly decreased survival following a 2-h recovery and inoculation with P. capsici (Fig. 2). Significant decreases in survival could not be detected when 4- or 24-h recovery periods were used (Fig. 3). P. capsici colonization of tomato seedlings, as estimated by $\mathrm{qPCR}$ of pathogen DNA, increased over time from 6 to $72 \mathrm{hpi}(P<0.0001)$. Exposure to a 6-h salinity stress and 2-h recovery prior to inoculation significantly increased pathogen colonization $(P=0.01)$ (Fig. 4). Saltstressed seedlings generally showed severe symptoms at $48 \mathrm{hpi}$ and died by $72 \mathrm{hpi}$, whereas nonstressed seedlings had milder symptoms at 72 hpi than the stressed seedlings did at $48 \mathrm{hpi}$. Based on these results, 48 hpi was chosen for routine comparisons of treatments.

Time course for ABA induction. Salt stress rapidly induced ABA in roots in hydroponically grown WT tomato plants at the four- to six-true-leaf stage. An increase in ABA was detectable within $1 \mathrm{~h}$ of exposure of the roots to salt under this experimental regime, and levels were on an upward trajectory at the termination

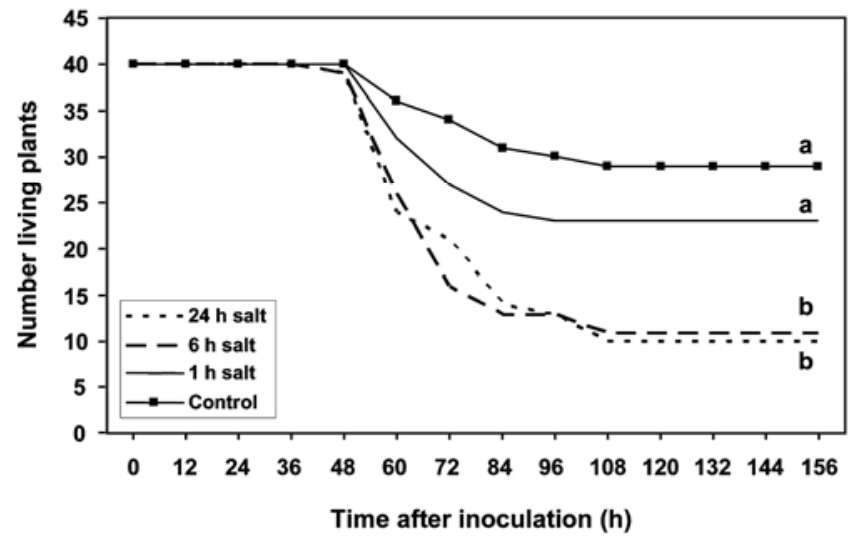

Fig. 2. Survival of tomato seedlings (cv. New Yorker) not exposed (control) or exposed to salt stress for 1,6 , or $24 \mathrm{~h}$ prior to a 2 -h recovery and inoculation. Experiments were conducted in the medium hydroponic format (two- to threetrue-leaf stage). Letters indicate significant differences at $P=0.05$ ( $n=40$ for each treatment). Roots were inoculated with Phytophthora capsici at $10^{5}$ zoospores $\mathrm{ml}^{-1}$. of sampling at $24 \mathrm{~h}$ (Fig. 5A). There are several wilty mutants in tomato that show varying degrees of ABA deficiency (51). One of these, flacca, with $\approx 21 \%$ of WT shoot basal ABA levels (26), lacks the ability for sulfurylation of the molybdenum cofactor (Moco) required for the terminal aldehyde oxidase step in ABA biosynthesis (45). We found that roots of the flacca mutant, unlike the salt-stressed roots of the isogenic WT Rheinlands Ruhm, did not accumulate ABA in response to salt and remained similar to or below the levels in the control (no-salt) roots throughout the time course observed. ABA levels in roots of tomato plants with two true leaves in the medium-format hydroponic regime peaked after $\approx 3 \mathrm{~h}$ of salinity exposure, remained elevated until at least $9 \mathrm{~h}$, and then returned to near baseline levels by $24 \mathrm{~h}$ (Fig. 5B).

Predisposition in ABA-deficient mutants. The ABA-deficient mutant sitiens appears to be defective in the structural gene encoding the ABA aldehyde oxidase (45), and is the most severely depressed in levels of endogenous ABA compared with other tomato ABA mutants, with only $\approx 8 \%$ of the shoot basal ABA levels as in the WT (26). Sitiens tomato seedlings were significantly less susceptible to $P$. capsici than seedlings of the isogenic Rheinlands Ruhm, and did not exhibit a predisposition reaction

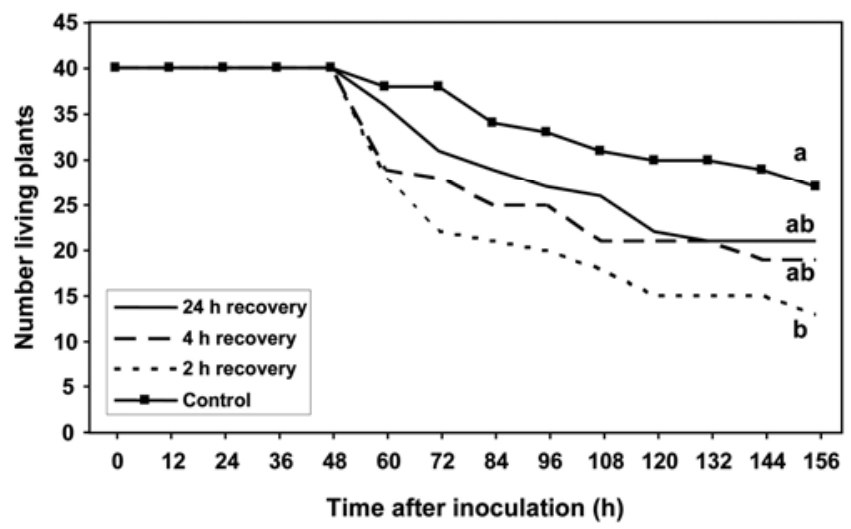

Fig. 3. Survival of tomato seedlings (cv. New Yorker) not exposed (control) or exposed to salt stress for $6 \mathrm{~h}$ and allowed to recover for 2, 4, or $24 \mathrm{~h}$ prior to inoculation. Experiments were conducted in the medium hydroponic format (two- to three-true-leaf stage). Letters indicate significant differences at $P=$ 0.05 ( $n=40$ for each treatment). Roots were inoculated with Phytophthora capsici at $10^{5}$ zoospores $\mathrm{ml}^{-1}$.

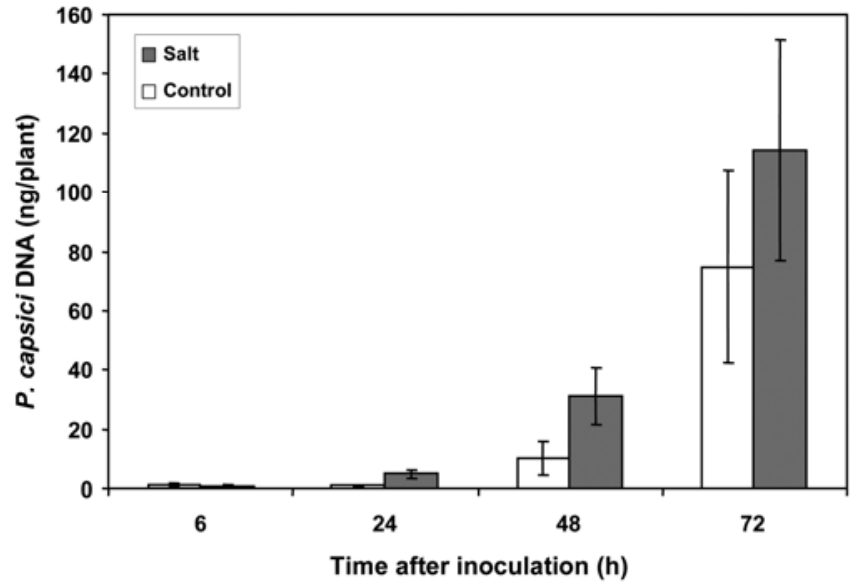

Fig. 4. Phytophthora capsici colonization of wild-type tomato seedlings (cv. New Yorker) in the petri dish assay at 6 to $72 \mathrm{~h}$ postinoculation when not exposed (control) or exposed to salt stress for $6 \mathrm{~h}$ prior to inoculation. Colonization, as estimated by quantitative polymerase chain reaction of pathogen DNA, increased significantly over time $(P<0.0001)$ and when plants were exposed to salt stress $(P=0.0448)$ (error bars represent the mean \pm standard error, $n=20$ for each treatment). Hypocotyls were inoculated with $10 \mu \mathrm{l}$ of $P$. capsici at $10^{5}$ zoospores $\mathrm{ml}^{-1}$. 
when exposed to $6 \mathrm{~h}$ of salinity and a 2-h recovery prior to inoculation (Fig. 6). Sitiens seedlings also failed to support significantly higher levels of $P$. capsici growth following a stress episode of $6 \mathrm{~h}$ of salinity and a 2-h recovery prior to inoculation (Fig. 7). Unlike the Rheinlands Ruhm seedlings, the sitiens seedlings did not accumulate ABA in response to salt (data not shown). Application of ( \pm )-ABA to sitiens seedlings for $24 \mathrm{~h}$ prior to the recovery period and inoculation significantly increased pathogen development in the host tissue (Fig. 7).

Because of the difficulty in maintaining wilty mutants without complementation with exogenous ABA under routine growth conditions, especially in older plants, we developed a petri dish assay using 2-week-old seedlings with fully expanded cotyledons but prior to the development of true leaves. The initial series of experiments measured disease developing from a point inoculation by extraction and measurement of brown, esterified phenolic oxidation products remaining in lesioned hypocotyls after removal of free phenolics and pigments with methanol. The assay is rapid and based on a method used for evaluating browning of potato disks following treatment with cell death elicitors (25). The assay corresponded well with visual estimation of browning and
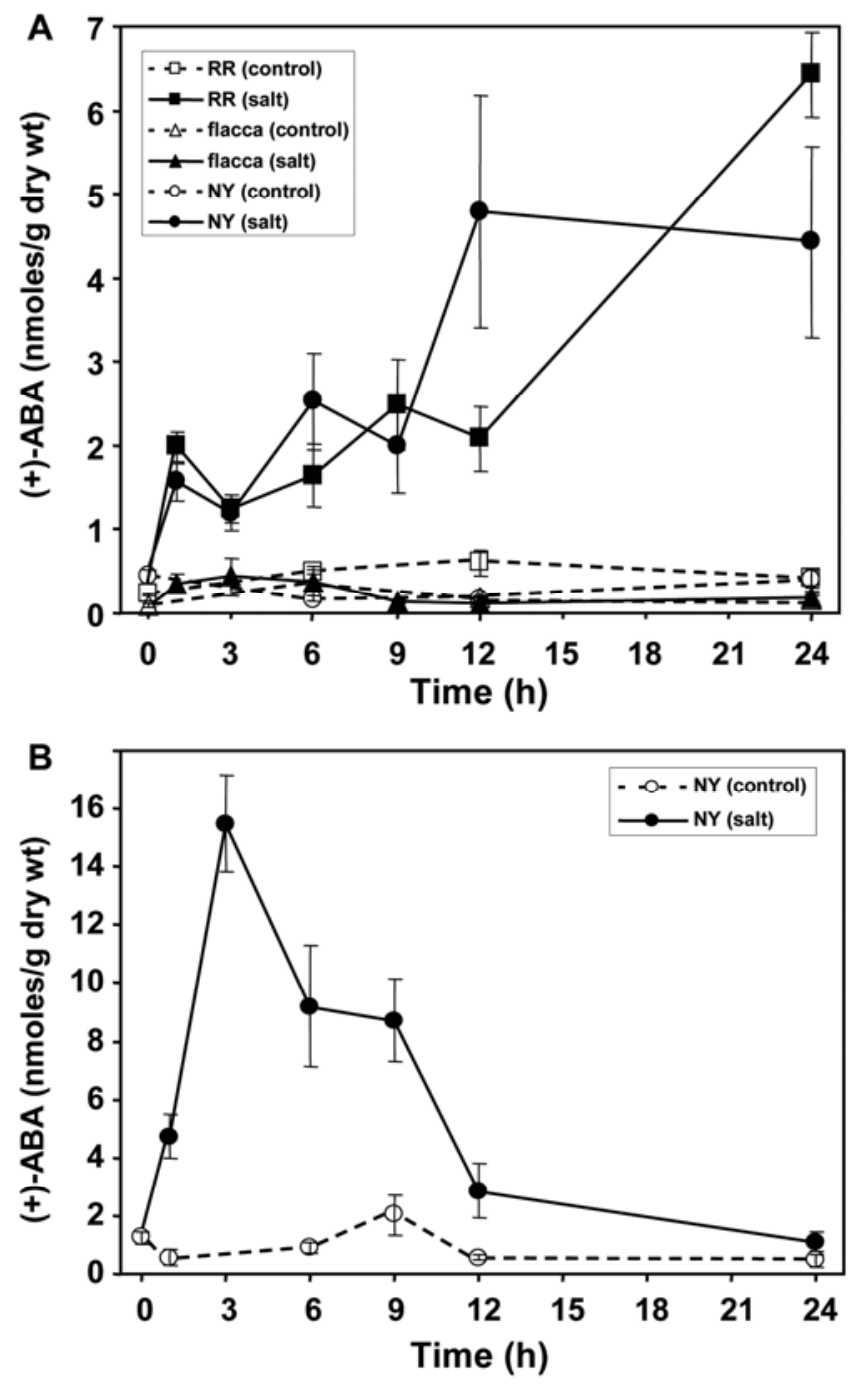

Fig. 5. Time course of abscisic acid (ABA) accumulation in tomato roots not exposed (control) or exposed to salt $\left(0.2 \mathrm{M} \mathrm{NaCl}\right.$ and $\left.0.02 \mathrm{M} \mathrm{CaCl}_{2}\right)$. Plants were grown hydroponically. A, ABA accumulation in roots of large (four to six true leaves) plants of wild-type 'Rheinlands Ruhm' (RR), 'New Yorker' (NY), and the ABA-deficient mutant flacca. Error bars represent the mean and standard error (SE) from two experiments. B, ABA accumulation in roots of medium (two to three true leaves) plants of NY. Error bars represent the mean and SE from two experiments. disease as a function of increasing inoculum density in the range of 1 to 1,000 zoospores per tomato hypocotyl (Supplemental Figure S2). With this assay, both WT genotypes, Rheinlands Ruhm and New Yorker, displayed a significant predisposition phenotype (Fig. 8). However, as with the experiments with the larger seedlings, the sitiens mutant did not show the predisposition phenotype $(P=0.48)$, and appeared significantly less diseased than Rheinlands Ruhm in both the control $(F=4.41, P=$ $0.042)$ and the salt $(F=10.1, P=0.003)$ treatments. Although the flacca mutant appeared to be somewhat more susceptible than sitiens, disease severity in salt-stressed flacca seedlings was not significantly different than the corresponding nonstressed flacca control $(P=0.10)$. The notabilis mutant, which targets the 9-cisepoxycarotenoid dioxygenase in ABA biosynthesis (45) and is the least ABA-deficient member of the series, with $\approx 47 \%$ of WT basal ABA levels (26), did not display predisposition and responded similarly to the WT to salt stress (data not shown).

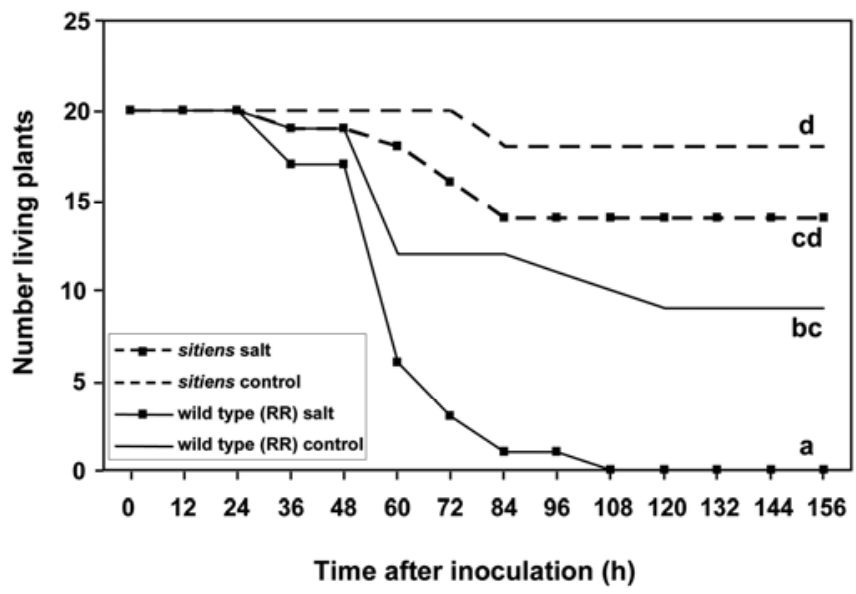

Fig. 6. Survival of wild-type 'Rheinlands Ruhm' (RR) and abscisic acid (ABA)-deficient sitiens tomato seedlings not exposed (control) or exposed to salt $\left(0.2 \mathrm{M} \mathrm{NaCl}\right.$ and $\left.0.02 \mathrm{M} \mathrm{CaCl}_{2}\right)$ for $6 \mathrm{~h}$ prior to $2 \mathrm{~h}$ of recovery and inoculation (Phytophthora capsici at $10^{5}$ zoospores $\mathrm{ml}^{-1}$ ). Experiments were conducted in the medium hydroponic format (two to three true leaves). Letters indicate significant differences at $P=0.05$ ( $n=20$ for each treatment).

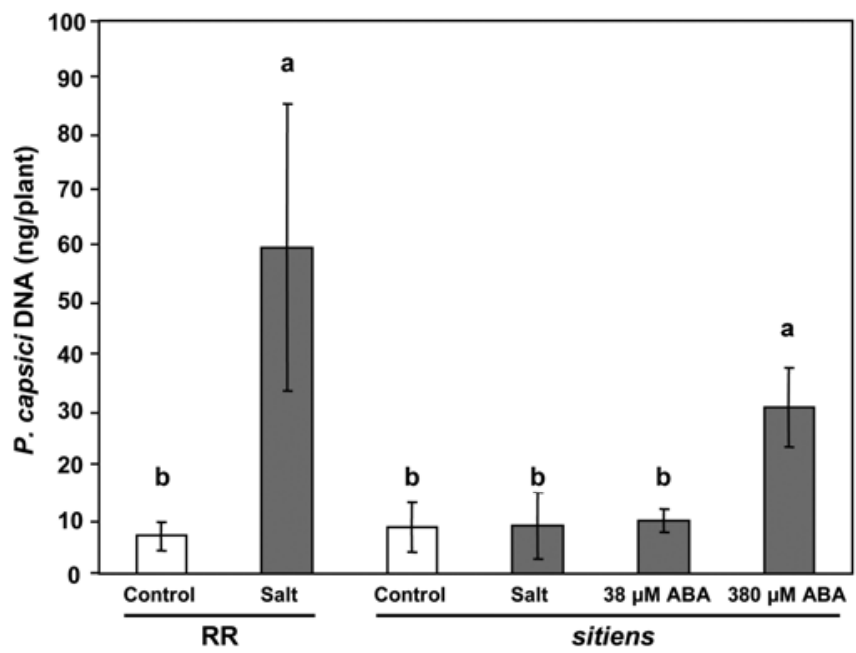

Fig. 7. Phytophthora capsici colonization $48 \mathrm{~h}$ postinoculation on wild-type 'Rheinlands Ruhm' (RR) and abscisic acid (ABA)-deficient sitiens tomato seedlings not exposed (control) or exposed to salt $(0.2 \mathrm{M} \mathrm{NaCl}$ and $0.02 \mathrm{M}$ $\mathrm{CaCl}_{2}$ ) for $6 \mathrm{~h}$ or supplemented with exogenous $( \pm)$-ABA at the indicated concentrations in the small-format petri dish assay (cotyledon stage). Colonization estimated by quantitative polymerase chain reaction of pathogen DNA. Letters indicate significant differences at $P=0.05$ (error bars represent the mean \pm standard error, $n=20$ for each treatment). Hypocotyls were inoculated with $10 \mu \mathrm{l}$ of $P$. capsici at $10^{5}$ zoospores $\mathrm{ml}^{-1}$. 
As a further test of the participation of $\mathrm{ABA}$ in predisposition and disease, seedlings in the petri dish and two-true-leaf stage assays were treated with fluridone. Fluridone inhibits ABA synthesis through its action on carotenoid biosynthesis at the level of phytoene desaturase (14). Exposure of tomato roots to fluridone over a concentration range of 10 to $100 \mu \mathrm{M}$ prior to inoculation reduced the salt-stress-induced increase in symptom expression and pathogen colonization in the two-true-leaf seedling assay (Supplemental Figure S3). However, fluridone at the highest concentration tested only depressed salt-induced ABA levels by $50 \%$ relative to the control. Also, exudates from fluridone-treated tomato roots were not as attractive to zoospores as assessed by the swim-in motility assay (data not shown). Thus, fluridone's impact on ABA levels and disease predisposition in this system was modest at best, and we cannot rule out other effects of this inhibitor.

Assessment of predisposition to Phytophthora root and crown rot in ethylene-modified tomato plants. Ethylene induction is a common response in plants to various biotic and abiotic stresses (40), and ethylene can modify resistance and susceptibility to pathogens through interaction with other phytohormone signals (23). We assessed the contribution of ethylene to predisposition under our experimental regime, which involves a relatively brief episode of salinity stress. The $\mathrm{Nr}$ mutant of tomato is a ripening-impaired mutant that has altered ethylene perception as a result of a mutation in the LeETRI gene $(30,58)$. P. capsici colonization was similar on both the WT (cv. Rutgers) and $\mathrm{Nr}$ plants, and salt stress resulted in a similar enhancement of pathogen development on both WT and $N r$ plants (Supplemental Figure S4). Ethylene production following a 16-h salt-stress episode in seedlings of $\mathrm{Nr}$ and sitiens and their corresponding WT controls (Rutgers and Rheinlands Ruhm, respectively) was not significantly different than the nonstressed control seedlings (Supplemental Figure S5). Also, ABA levels in salt-treated Rutgers and $\mathrm{Nr}$ plants were similar (data not shown).

\section{DISCUSSION}

In this study, we demonstrated that exogenous ABA can mimic the salinity-induced susceptibility of tomato and chrysanthemum roots to Phytophthora spp. and that endogenous root ABA levels are strongly associated with the onset of salinity-induced susceptibility of tomato to root and crown rot caused by $P$. capsici. This association was found using different assay formats and involved rating disease incidence and severity as well as estimating colonization by measurement of pathogen DNA in host tissue. Tomato plants showed significant increases in susceptibility to $P$. capsici with 6- and 24-h exposures to salinity stress. This induced state of susceptibility persisted for at least $2 \mathrm{~h}$ and likely up to $24 \mathrm{~h}$ following removal of the stress. Imposition of stress or treatment of the roots with ABA either before or after inoculation had similar outcomes on disease. The stress-induced increase in root ABA levels preceded or temporally paralleled the predisposition onset following salt exposure. In larger plants (four to six true leaves), root $\mathrm{ABA}$ levels were elevated at the time of inoculation whereas, in younger tomato seedlings (two true leaves), root ABA levels peaked rapidly at $3 \mathrm{~h}$ and declined thereafter (Fig. 5), such that ABA levels in plants inoculated after a 24-h stress episode had returned to near the levels in nonstressed plants. This further establishes that the effect of ABA on susceptibility persists for a time following return to near basal levels.

Pathogen colonization of tomato seedlings as estimated by qPCR increased from 6 through 72 hpi. Seedlings that were exposed to 6-h salinity stress and then inoculated following a 2-h recovery period showed increasing levels of colonization at each time point. Seedlings of the ABA-deficient tomato mutant sitiens exhibited not only greater resistance to $P$. capsici overall but also failed to display stress-induced susceptibility when exposed to salt. Both findings are consistent with the hypothesized role of ABA in predisposition. Seedlings of the sitiens mutant failed to support increased accumulation of $P$. capsici biomass at $48 \mathrm{hpi}$, as measured by qPCR. Chemical complementation of ABA-deficient mutants through application of exogenous ABA induced a degree of susceptibility to $P$. capsici similar to that observed in WT plants. The strong effect on predisposition of the sitiens mutant relative to that observed with the flacca and notabilis mutants, which are less severe in the wilty phenotype, may relate to their relative levels of ABA. Collectively, the results of the present study reinforce that $\mathrm{ABA}$ is an important component in pathways leading to the enhanced susceptibility to Phytophthora root and crown rot following an episode of abiotic root stress, and are consistent with studies recently reported for $P$. ramorum on Rhododendron spp. (44).

Our findings also are consistent with studies that found sitiens plants to be less susceptible to bacterial and fungal pathogens unless supplied with exogenous ABA. Sitiens plants exhibit stronger and more rapid disease defense responses to foliar pathogens, marked by greater production of reactive oxygen species, which may influence disease progression through modification of cell wall structure or defense signaling $(3,4)$. Similarly, some bacterial pathogens appear to manipulate host ABA signaling in order to establish disease, with ABA-deficient mutants being less susceptible unless complemented with exogenous ABA (16). ABA deficiency-mediated resistance to disease has also been associated with increased callose deposition $(16,54,56)$. It has been suggested that $\mathrm{ABA}$ crosstalk operates through priming for innate defense responses or the modification of other phytohormone pathways (53).

We were unable to discern a significant contribution of ethylene with Phytophthora root and crown rot disease severity in tomato. This is in contrast to diseases caused by leaf spotting bacteria and by the wilt pathogen Fusarium oxysporum f. sp. lycopersici,

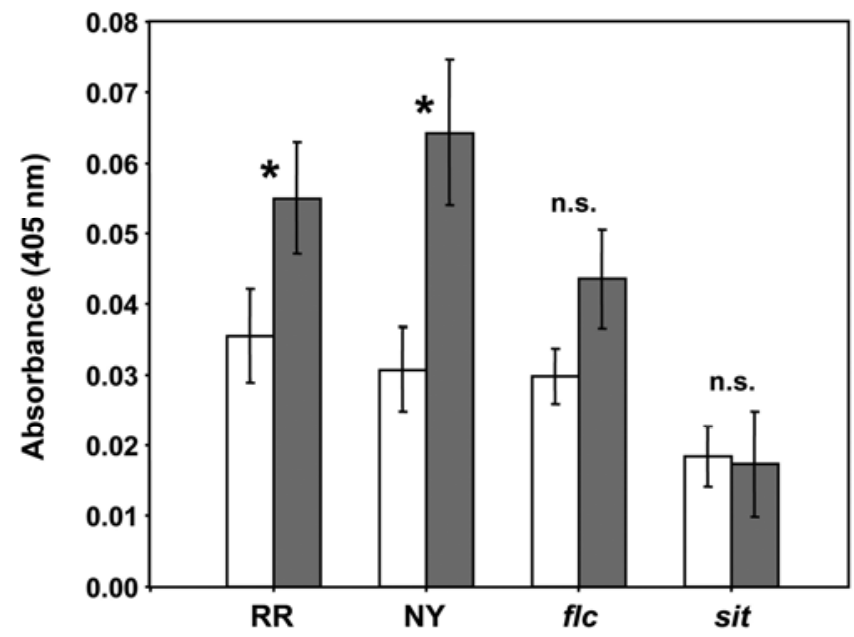

Fig. 8. Effect of root salinity stress ( $16 \mathrm{~h}$ ) on disease severity (necrotic lesions) as measured by the base-extracted oxidized phenolics in tomato hypocotyls of abscisic acid (ABA)-normal 'Rheinlands Ruhm' (RR) and 'New Yorker' (NY) and ABA-deficient flacca (flc) and sitiens (sit) genotypes, $72 \mathrm{~h}$ postinoculation. Experiments were conducted in the small-format petri dish assay (cotyledon stage). Values for noninoculated plants for each treatment have been subtracted from the inoculated values. Open bars represent nonstressed controls and solid bars represent salt stressed treatments. Error bars represent the mean and standard error from five experiments, $n=20$ for each mean. Plants were inoculated with Phytophthora capsici isolate 1509 (10 $\mu \mathrm{l} / \mathrm{hypo-}$ cotyl at $10^{4}$ zoospores $\mathrm{ml}^{-1}$ ). Asterisks indicate that differences between control and salt-treated values for RR and NY are significant at $P=0.07$ and 0.009 , respectively ( $t$ test). Control and salt-treated values for flacca and sitiens are not significantly (n.s.) different $(P=0.10$ and 0.48 , respectively). Control and salt-treated values for sitiens are significantly different from the corresponding values for RR by least squares analysis (control: $F=4.41 ; P=$ 0.04 ; salt: $F=10.1 ; P=0.003)$. 
where disease by these pathogens was much reduced in the $\mathrm{Nr}$ mutant (31). Alteration of ethylene perception in tomato markedly reduces the toxicity of sphinganine analog mycotoxins that elicit PCD in tomato (39). In the latter cases, experiments were conducted with plants at a later stage of development. Ethylene can interact with ABA and can be elevated in ABA-deficient plants, possibly accounting for the impairment of shoot growth commonly observed in such mutants (46). However, within our stress regime and seedling assay, we could not see evidence for an interaction between the two phytohormones in predisposition, and ethylene production by WT and sitiens tomato plants was similar in our experimental format (Supplemental Figure S5). Although exposure of tomato roots to salinity for days or weeks will induce ethylene synthesis, this occurs well after ABA induction (1). Also, ethylene synthesis is not triggered by water deficit and osmotic stress in intact plants (41). Thus, our results are perhaps not surprising given the nature and relatively short duration of the abiotic stress imposed in our experiments.

Salinity stress can result in greater attraction of zoospores to roots (32). This in itself cannot fully account for the severe predisposing effect of the stress because there are strong effects of salinity on cytological defenses in roots (49). Furthermore, in ongoing research in our laboratory, exudates from salt-stressed sitiens and WT tomato roots are equally attractive to $P$. capsici zoospores under our conditions (data not shown). This reinforces the view that the principal impact of ABA signaling in mediating stress-induced susceptibility is at the level of host response during infection and colonization rather than during prepenetration events.

The results of this and other predisposition studies raise questions about how plants are "primed" for susceptibility following a stress episode and the transient rise in ABA levels. In Arabidopsis, ABA interferes with salicylate-mediated defenses and salt stress compromises systemic acquired resistance (SAR) by an ABA-dependent process (57). Nonetheless, it is still unresolved how salicylate-mediated responses, despite the plethora of studies on SAR, stop or contain a pathogen. Are stressed plants altered in their sensitivity to effectors of apoptosis, or PCD? In yeast, hyperosmotic stress will induce PCD (47) and anti-apoptotic genes, when expressed in tobacco, provide some protection against water stress (7). PCD pathway regulation in plants is poorly understood. However, studies with various mutants point to multiple targets for study and intervention and possible role in predisposition. Cell death from the plant's perspective can be beneficial (lesion restriction) or detrimental ("runaway" death and lesion expansion), thus establishing that any relationship between PCD and stress-induced susceptibility will likely depend upon the particular host-parasite interaction (20). In addition, it will be important to determine whether oomycete pathogens target ABA signaling directly via an effector-mediated process, as appears to be the case with Pseudomonas syringae pv. tomato in compatible interactions (16).

The anticipated consequences of climate change likely will exacerbate the occurrence of predisposition in some production areas, and could limit or complicate options for disease management (15). Thus, understanding how diverse abiotic stresses influence biotic interactions is critically important and urgent (9). There is a need for tractable models for mechanistic studies of predisposition. Given the importance of abiotic stress in the onset and severity of many Phytophthora diseases, the tomato-Phytophthora capsici interaction provides a system that is well suited for such studies and one that is complementary to models such as Arabidopsis that are used in plant stress biology.

\section{ACKNOWLEDGMENTS}

M. DiLeo was supported, in part, by a fellowship from the Department of Homeland Security, and by grants to D. M. Rizzo from the United
States Department of Agriculture (USDA) Forest Service Pacific Southwest Research Station and the Gordon and Betty Moore Foundation. Research was supported, in part, by a grant to R. M. Bostock from the USDA Exotic/Invasive Pests and Diseases program and with funds from the University of California Agricultural Experiment Station. Initial research was supported by USDA-NRICGP grant no. 88-37151-3693 to R. M. Bostock, J. D. MacDonald, and J. M. Duniway. We thank M. Flores, C. Hurley, S. Madden, and J. Stites for their capable assistance and contributions in portions of this study; and W. Biasi of the University of California-Davis Postharvest Laboratory, Department of Plant Sciences, for assistance with the ethylene analyses.

\section{LITERATURE CITED}

1. Albacete, A., Ghanem, M. E., Martinez-Andujar, C., Acosta, M., SanchezBravo, J., Martinez, V., Lutts, S., Dodd, I. C., and Perez-Alfocea, F. 2008. Hormonal changes in relation to biomass partitioning and shoot growth impairment in salinized tomato (Solanum lycopersicum L.) plants. J. Exp. Bot. 59:4119-4131.

2. Anderson, J. P., Badruzsaufari, E., Schenk, P. M., Manners, J. M., Desmond, O. J., Ehlert, C., Maclean, D. J., Ebert, P. R., and Kazan, K. 2004. Antagonistic interaction between abscisic acid and jasmonateethylene signaling pathways modulates defense gene expression and disease resistance in Arabidopsis. Plant Cell 16:3460-3479.

3. Asselbergh, B., Achuo, A. E., Hofte, M., and Van Gijsegem, F. 2008. Abscisic acid deficiency leads to rapid activation of tomato defence responses upon infection with Erwinia chrysanthemi. Mol. Plant Pathol. 9:11-24.

4. Asselbergh, B., Curvers, K., Franca, S. C., Audenaert, K., Vuylsteke, M., Van Breusegem, F., and Hofte, M. 2007. Resistance to Botrytis cinerea in sitiens, an abscisic acid-deficient tomato mutant, involves timely production of hydrogen peroxide and cell wall modifications in the epidermis. Plant Physiol. 144:1863-1877.

5. Asselbergh, B., De Vleesschauwer, D., and Hofte, M. 2008. Global switches and fine-tuning: ABA modulates plant pathogen defense. Mol. Plant-Microbe Interact. 21:709-719.

6. Audenaert, K., De Meyer, G. B., and Hofte, M. M. 2002. Abscisic acid determines basal susceptibility of tomato to Botrytis cinerea and suppresses salicylic acid-dependent signaling mechanisms. Plant Physiol. 128:491-501.

7. Awada, T., Dunigan, D. D., and Dickman, M. B. 2003. Animal antiapoptotic genes ameliorate the loss of turgor in water-stressed transgenic tobacco. Can. J. Plant Sci. 83:499-506.

8. Bartels, D., and Sunkar, R. 2005. Drought and salt tolerance in plants. Crit. Rev. Plant Sci. 24:23-58.

9. Bostock, R. M. 2005. Signal crosstalk and induced resistance: straddling the line between cost and benefit. Annu. Rev. Phytopathol. 43:545-580.

10. Bostock, R. M., Macdonald, J. D., Duniway, J. M., and Stites, J. 1990. Abscisic acid as a determinant of host susceptibility in salinity predisposition to Phytophthora root rot in chrysanthemum and tomato. (Abstr.) Phytopathology 80:1023.

11. Boyer, J. S. 1995. Biochemical and biophysical aspects of water deficits and the predisposition to disease. Annu. Rev. Phytopathol. 33:251-274.

12. Cahill, D. M., and Ward, E. W. B. 1989. An indirect enzyme linked immunosorbent-assay for measurement of abscisic acid in soybean inoculated with Phytophthora megasperma f. sp. glycinea. Phytopathology 79:1238-1242.

13. Cahill, D. M., and Ward, E. W. B. 1989. Rapid localized changes in abscisic acid concentrations in soybean in interactions with Phytophthora megasperma f. sp. glycinea or after treatment with elicitors. Physiol. Mol. Plant Pathol. 35:483-494.

14. Chamovitz, D., Sandmann, G., and Hirschberg, J. 1993. Molecular and biochemical characterization of herbicide resistant mutants of cyanobacteria reveals that phytoene desaturation is a rate-limiting step in carotenoid biosynthesis. J. Biol. Chem. 268:17348-17353.

15. Coakley, S. M., Scherm, H., and Chakraborty, S. 1999. Climate change and plant disease management. Annu. Rev. Phytopathol. 37:399-426.

16. de Torres-Zabala, M., Truman, W., Bennett, M. H., Lafforgue, G., Mansfield, J. W., Egea, P. R., Bogre, L., and Grant, M. 2007. Pseudomonas syringae pv. tomato hijacks the Arabidopsis abscisic acid signalling pathway to cause disease. EMBO J. 26:1434-1443.

17. Dhingra, O. D., and Sinclair, J. B. 1995. Basic Plant Pathology Methods, 2nd ed. CRC Press, Boca Raton, FL.

18. Duniway, J. M. 1977. Predisposing effect of water stress on severity of Phytophthora root-rot in safflower. Phytopathology 67:884-889.

19. Fan, J., Hill, L., Crooks, C., Doerner, P., and Lamb, C. 2009. Abscisic acid has a key role in modulating diverse plant-pathogen interactions. Plant Physiol. 150:1750-1761.

20. Gilchrist, D. G. 1998. Programmed cell death in plant disease: The 
purpose and promise of cellular suicide. Annu. Rev. Phytopathol. 36:393414.

21. Glazebrook, J. 2005. Contrasting mechanisms of defense against biotrophic and necrotrophic pathogens. Annu. Rev. Phytopathol. 43:205227.

22. Govers, F., and Gijzen, M. 2006. Phytophthora genomics: The plant destroyers' genome decoded. Mol. Plant-Microbe Interact. 19:1295-1301.

23. Grant, M. R., and J. D. G. Jones. 2009. Hormone (dis)harmony moulds plant health and disease. Science 324:750-752.

24. Henfling, J., Bostock, R., and Kuć, J. 1980. Effect of abscisic acid on rishitin and lubimin accumulation and resistance to Phytophthora infestans and Cladosporium cucumerinum in potato tuber tissue slices. Phytopathology 70:1074-1078.

25. Henfling, J. W. D. M., Bostock, R. M., and Kuć, J. 1980. Cell walls of Phytophthora infestans contain an elicitor of terpene accumulation in potato tubers. Phytopathology 70:772-776.

26. Herde, O., Pena Cortes, H., Wasternack, C., Willmitzer, L., and Fisahn, J. 1999. Electric signaling and $P i \mathrm{~N}_{2}$ gene expression on different abiotic stimuli depend on a distinct threshold level of endogenous abscisic acid in several abscisic acid-deficient tomato mutants. Plant Physiol. 119:213218.

27. Hoagland, D., and Aron, D. 1950. The water culture method for growing plants without soil. Calif. Agric. Exp. Stn. Circ. 347:32.

28. Kramer, P. J., and Boyer, J. S. 1995. Water Relations of Plants and Soils. Academic Press, San Diego, CA

29. Kuan, T. L., and Erwin, D. C. 1980. Predisposition effect of water saturation of soil on Phytophthora megasperma f. sp. medicaginis root rot of alfalfa Medicago sativa. Phytopathology 70:981-986.

30. Lanahan, M. B., Yen, H. C., Giovannoni, J. J., and Klee, H. J. 1994. The Never ripe mutation blocks ethylene perception in tomato. Plant Cell 6:521-530.

31. Lund, S. T., Stall, R. E., and Klee, H. J. 1998. Ethylene regulates the susceptible response to pathogen infection in tomato. Plant Cell 10:371382.

32. MacDonald, J. D. 1982. Effect of salinity stress on the development of Phytophthora root rot of chrysanthemum Chrysanthemum morifolium cultivar Paragon. Phytopathology 72:214-265.

33. MacDonald, J. D. 1984. Salinity effects on the susceptibility of chrysanthemum roots to Phytophthora cryptogea. Phytopathology 74:621-624.

34. Mauch-Mani, B., and Mauch, F. 2005. The role of abscisic acid in plantpathogen interactions. Curr. Opin. Plant Biol. 8:409-414.

35. McDonald, K. L., and Cahill, D. M. 1999. Influence of abscisic acid and the abscisic acid biosynthesis inhibitor, norflurazon, on interactions between Phytophthora sojae and soybean (Glycine max). Eur. J. Plant Pathol. 105:651-658.

36. Mohr, P. G., and Cahill, D. M. 2001. Relative roles of glyceollin, lignin and the hypersensitive response and the influence of ABA in compatible and incompatible interactions of soybeans with Phytophthora sojae. Physiol. Mol. Plant Pathol. 58:31-41.

37. Mohr, P. G., and Cahill, D. M. 2003. Abscisic acid influences the susceptibility of Arabidopsis thaliana to Pseudomonas syringae pv. tomato and Peronospora parasitica. Funct. Plant Biol. 30:461-469.

38. Mohr, P. G., and Cahill, D. M. 2007. Suppression by ABA of salicylic acid and lignin accumulation and the expression of multiple genes, in Arabidopsis infected with Pseudomonas syringae pv. tomato. Funct. Integr. Genomics 7:181-191.

39. Moore, T., Martineau, B., Bostock, R. M., Lincoln, J. E., and Gilchrist, D. G. 1999. Molecular and genetic characterization of ethylene involvement in mycotoxin-induced plant cell death. Physiol. Mol. Plant Pathol. 54:73-85.
40. Morgan, P. W., and Drew, M. C. 1997. Ethylene and plant responses to stress. Physiol. Plant. 100:620-630.

41. Morgan, P. W., He, C. J., Degreef, J. A., and Deproft, M. P. 1990. Does water deficit stress promote ethylene synthesis by intact plants? Plant Physiol. 94:1616-1624.

42. Morris, P. F., and Ward, E. W. B. 1992. Chemoattraction of zoospores of the soybean pathogen, Phytophthora sojae, by isoflavones. Physiol. Mol. Plant Pathol. 40:17-22.

43. Ristaino, J. B., and Duniway, J. M. 1989. Effect of preinoculation and postinoculation water-stress on the severity of Phytophthora root-rot in processing tomatoes. Plant Dis. 73:349-352.

44. Roubtsova, T. V., and Bostock, R. M. 2009. Episodic abiotic stress as a potential contributing factor to onset and severity of disease caused by Phytophthora ramorum in Rhododendron and Viburnum. Plant Dis. 93:912-918.

45. Seo, M., and Koshiba, T. 2002. Complex regulation of ABA biosynthesis in plants. Trends Plant Sci. 7:41-48.

46. Sharp, R. E., LeNoble, M. E., Else, M. A., Thorne, E. T., and Gherardi, F. 2000. Endogenous ABA maintains shoot growth in tomato independently of effects on plant water balance: Evidence for an interaction with ethylene. J. Exp. Bot. 51:1575-1584.

47. Silva, R. D., Sotoca, R., Johansson, B., Ludovico, P., Sansonetty, F., Silva, M. T., Peinado, J. M., and Corte-Real, M. 2005. Hyperosmotic stress induces metacaspase- and mitochondria-dependent apoptosis in Saccharomyces cerevisiae. Mol. Microbiol. 58:824-834.

48. Silvar, C., Diaz, J., and Merino, F. 2005. Real-time polymerase chain reaction quantification of Phytophthora capsici in different pepper genotypes. Phytopathology 95:1423-1429.

49. Swiecki, T. J., and MacDonald, J. D. 1988. Histology of chrysanthemum roots exposed to salinity stress and Phytophthora cryptogea. Can. J. Bot. 66:280-288.

50. Swiecki, T. J., and MacDonald, J. D. 1991. Soil salinity enhances Phytophthora root rot of tomato but hinders asexual reproduction by Phytophthora parasitica. J. Am. Soc. Hortic. Sci. 116:471-477.

51. Tal, M., and Nevo, Y. 1973. Abnormal stomatal behavior and root resistance, and hormonal imbalance in 3 wilty mutants of tomato. Biochem. Genet. 8:291-300.

52. Thaler, J. S., and Bostock, R. M. 2004. Interactions between abscisicacid-mediated responses and plant resistance to pathogens and insects. Ecology 85:48-58

53. Ton, J., Flors, V., and Mauch-Mani, B. 2009. The multifaceted role of ABA in disease resistance. Trends Plant Sci. 14:310-317.

54. Ton, J., and Mauch-Mani, B. 2004. B-Amino-butyric acid-induced resistance against necrotrophic pathogens is based on ABA-dependent priming for callose. Plant J. 38:119-130.

55. Verslues, P. E., and Zhu, J. K. 2005. Before and beyond ABA: Upstream sensing and internal signals that determine ABA accumulation and response under abiotic stress. Biochem. Soc. Trans. 33:375-379.

56. Wiese, J., Kranz, T., and Schubert, S. 2004. Induction of pathogen resistance in barley by abiotic stress. Plant Biol. 6:529-536.

57. Yasuda, M., Ishikawa, A., Jikumaru, Y., Seki, M., Umezawa, T., Asami, T., Maruyama-Nakashita, A., Kudo, T., Shinozaki, K., Yoshida, S., and Nakashita, H. 2008. Antagonistic interaction between systemic acquired resistance and the abscisic acid-mediated abiotic stress response in Arabidopsis. Plant Cell 20:1678-1692.

58. Yen, H. C., Lee, S., Tanksley, S. D., Lanahan, M. B., Klee, H., and Giovannoni, J. J. 1995. The tomato Never-ripe locus regulates ethyleneinducible gene expression and is linked to a homolog of the Arabidopsis ETR 1 gene. Plant Physiol. 107:1343-1353. 